\title{
A communal nesting site of the Central American river turtle (Dermatemys mawii) along the New River, Belize
}

\author{
NICOLE D. JENNINGS ${ }^{1}$, EMILY V. GATI ${ }^{1}$, GERSON A. RAMIREZ ${ }^{2}$, JENNA COLE ${ }^{1}$, BRITTANY MASON ${ }^{1}$, \\ VENETIA BRIGGS-GONZALEZ ${ }^{1,2}$, \& FRANK J. MAZZOTTI ${ }^{1,2}$ \\ ${ }^{1}$ University of Florida IFAS Fort Lauderdale Research and Education Center, 3205 College Ave, Davie, FL, USA, 33314 \\ ${ }^{2}$ Lamanai Field Research Center, Indian Church, Orange Walk District, Belize, CA \\ ${ }^{*}$ Corresponding author e-mail: nicole.jennings@ufl.edu
}

\begin{abstract}
The Central American river turtle, Dermatemys mawii, is a critically endangered species with declines in its population caused by human harvest. Previous knowledge of nesting behaviour is minimal, and communal nesting of $D$. mawii has not been described previously. Here we report the first observations of communal nesting of $D$. mawii and provide recommendations to researchers and conservationists on how to find $D$. mawii nests, based on observed communal nesting conditions, proximity to water, hydro-period, and vegetative cover.
\end{abstract}

\section{INTRODUCTION}

$T^{\text {the }}$ he Central American river turtle, Dermatemys mawii (also known as the hicatee in Belize), is a large, aquatic freshwater turtle that is found in the lowlands of southern Mexico, northern Guatemala, and Belize (García-Anleu et al., 2007; Briggs-Gonzalez et al., 2018, 2019). Due to heavy hunting pressure, $D$. mawii populations have been severely reduced in Mexico, are in decline in Belize, and are of unknown status in Guatemala (Moll, 1986; Polisar, 1994, 1995; Rainwater et al., 2012). Dermatemys mawii is classified as Critically Endangered by the International Union for Conservation of Nature and listed on Appendix II of the Convention on International Trade in Endangered Species (CITES, 2009; IUCN, 2009).

Most of the existing information on the nesting ecology of $D$. mawii has been obtained by examining reproductive tracts of animals harvested for consumption (Polisar, 1995, 1996; Vogt et al., 2011). In addition, a few studies have reported on nests found in the wild (Polisar, 1996). Based on these observations, most nesting in $D$. mawii across its range occurs at the peak of the wet season between September and December, with a secondary nesting period in the early dry season from January to February (Polisar, 1996; Vogt et al., 2011).

Female $D$. mawii nest in moist soil along the shoreline, generally within $3 \mathrm{~m}$ of water in riparian forests and savannas (Polisar, 1995; Vogt et al., 2011). As a result, nests often become inundated during the rainy season. Nests are normally solitary and placed at scattered locations, often in dense cover, along the shoreline that afford some protection from human harvest (Vogt et al., 2011). Polisar (1995) found that local harvesters rarely discovered $D$. mawii nests, and none had witnessed hatchling emergence. Here we present the first observation of communal nesting of $D$. mawii from the New River in northern Belize.

\section{MATERIALS AND METHODS}

The study site was a side channel of the New River at the mouth of the New River Lagoon ( $17^{\circ} 47^{\prime} 5^{\prime \prime} \mathrm{N}, 88^{\circ} 38^{\prime} 54^{\prime \prime}$ W) in the Orange Walk District of northern Belize. The mean annual rainfall for this area is approximately $150 \mathrm{~cm}$, with peak water levels from September to December and the lowest in April and May (Hartshorn et al., 1984; Polisar, 1996). The site was about $25 \mathrm{~m}$ long, $15 \mathrm{~m}$ wide and, at the time, slightly elevated at about $60 \mathrm{~cm}$ above the waterline of the New River. Both shorelines of the side channel have extensive Cladium spp. marshes with small patches of trees located on relatively elevated areas.

We were able to locate the study site from information provided by a local resident, who had found eggshells while searching for firewood. On 9 January 2019, we visited the nest site and found the eggshells of previously hatched turtles, confirming turtle nesting activity. The nest site was approximately $15 \mathrm{~m}$ from the water's edge through a dense canopy (75-100 \%) of trees (Fig. 1A). The nest site itself was in a relatively open area with about $25 \%$ canopy cover (Fig. 1B). Surrounding flora included bromeliads (Aechmea bracteata, Tillandsia fasciculata, Billbergia viridiflora), dog-tail cactus (Selenicereus testudo), bullet trees (Bucida buceras), logwood (Haematoxylum campechianum), and provision trees (Pachira aquatica). The ground was composed primarily of a fibrous peat soil (Fig.1B).

We deployed three Moultrie M-880 camera traps at this site on 17 January 2019 to record and observe nesting behaviour and to determine if the site was being used by $D$. mawii. The cameras were set on 10-second motion detect intervals, recording 10 -second videos each time they were triggered. Infrared was used to capture videos during the night time. We checked cameras and searched for nests on 3 March 2019, 26 April 2019, and 24 June 2019. 


\section{RESULTS}

On 24 June 2019, we found six nests at the study site within $10 \mathrm{~m}$ of each other. These nests were $14 \mathrm{~m}-18 \mathrm{~m}$ from the water's edge. Akin to observations by Vogt et al. (2011), the nests were scattered and not easily identified. There were multiple eggshells near the openings of five nests, making them more apparent, and these nests were empty. The eggshells were brittle and all were similar in size, shape and texture. They also appeared fresh and naturally hatched rather than depredated, leading us to conclude the nests had been successful. One of these five nests was built beneath the exposed roots of a fallen bullet tree. The sixth nest was invaded by fire ants (Solenopsis invicta) and had no eggshells surrounding it. Nest appearance and dimensions were similar for all of the nests, with a circular entrance ranging from 7.2 $\mathrm{cm}$ to $9.6 \mathrm{~cm}$ (mean $8.8 \mathrm{~cm}$ ) in diameter, and extending to a depth of $9.6 \mathrm{~cm}$ to $13.3 \mathrm{~cm}$ (mean $11.2 \mathrm{~cm}$ ) (Fig. 1C). Upon gentle excavation of the sixth nest, we found eight hatchling D. mawii, six of which had already succumbed to fire ant predation (Fig. 1D). Hatchlings were identified as D. mawii based on characteristics recently described by Platt et al., (2019). The remaining two hatchlings were lethargic and exhibited extensive swelling from ant bites, which proved fatal within 24 hours. The eggshells found upon excavating the nest were the same size, shape and texture as those found scattered around the entrance of other nests. This observation confirmed that the site was being used by $D$. mawii for nesting.

We did not observe D. mawii or any other turtle species on the camera traps. However, we did capture videos of other animals at the nesting site, including raccoons (Procyon lotor), gray four-eyed opossums (Philander opossum), lowland pacas (Cuniculus paca), tapir (Tapirus bairdii), neotropical otters (Lontra longicaudis), northern tamanduas (Tamandua mexicana), white-nosed coatis (Nasua narica), green iguanas (Iguana iguana), great curassows (Crax rubra), and rufousnaped wood rails (Aramides albiventris). On eight occasions, video images captured coatis actively smelling around the location of the turtle nests, but no digging was observed.

\section{DISCUSSION}

In this study, we report an observation of communal nesting by $D$. mawii in the wild. Previous studies have reported solitary nests of D. mawii (Polisar, 1996; Vogt et al., 2011) but the possibility of communal nesting was not excluded. For example, Polisar (1996) found four D. mawii nests concentrated within $6 \mathrm{~m}$ of each other on an old logging road. Although in the current study, turtle identity was based on the observation of hatchlings in only one of the nests, there is strong evidence that the other five nests were of the same species, as egg shell remains were consistent with $D$. mawii. Other freshwater turtles, including the Mesoamerican slider (Trachemys venusta), overlap in range with $D$. mawii, but the two species have dissimilar preferences in nesting habitat (Moll \& Moll, 2004; Vogt \& Flores-Villela, 1992). The nesting behaviour and reproductive biology of $T$. venusta is similar to that of other slider populations except they have larger egg size, clutch size, and nest dimensions (Moll, 1994). Although $T$. venusta hatchlings emerge similarly to $D$. mawii, around May and June, their nests are typically constructed on upper parts of beach berms, usually under cocoplum vegetation (Moll, 1994). Open beach and forested areas are not used for T. venusta nesting (Moll, 1994; Moll \& Moll, 2004). Eggs of $T$. venusta are usually oblong and leathery and have a mean size of $38.1 \mathrm{~mm} \times 22.6 \mathrm{~mm}$ (Moll \& Moll, 1990; Vogt, 1990), while eggs of $D$. mawii are usually large and brittle-shelled with an ellipsoidal shape and a mean size of $61.6 \mathrm{~mm} \times 35.8$ $\mathrm{mm}$ (Polisar, 1996).
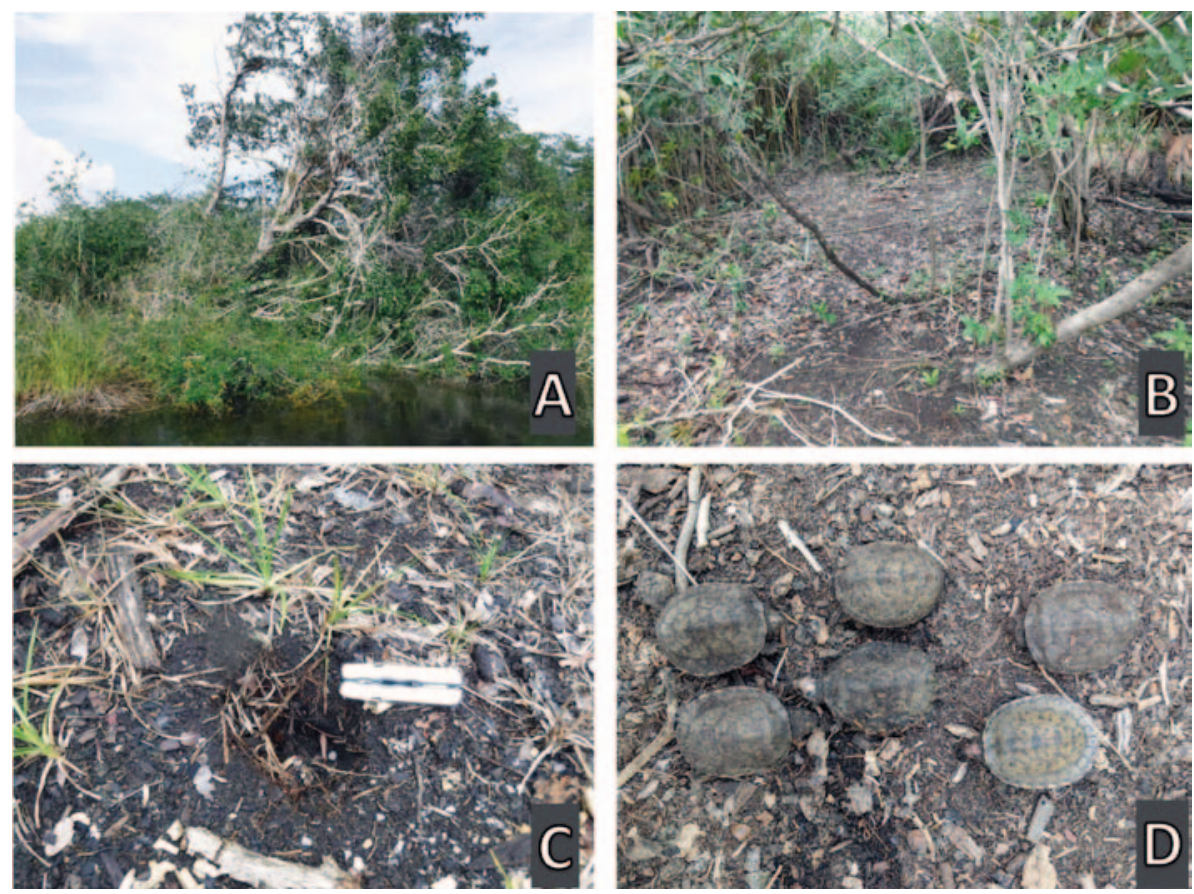

Figure 1. A. The hicatee (D. mawii) communal nesting site entrance from the New River, B. View of the site upon entering on foot, C. The nests were small and well hidden (Leatherman multi-tool $\sim 10 \mathrm{~cm}$ long, included for scale), D. Eight hatchlings in a nest with fire ants (S. invicta) present inside, six of which had succumbed to their predation 
The six nests we discovered were congregated in a small clearing, separated from the surrounding moderately dense vegetation. The site's elevation and open canopy provides suitable conditions for egg incubation. We hypothesise that communal nesting of $D$. mawii may have been influenced by lack of similar suitable habitat in surrounding areas due to low elevation and wet conditions. The distance of nests observed in this study from the water was greater than in previous observations (Polisar, 1996; Vogt et al., 2011). This may be explained by the combination of elevation and open canopy at the former. It is also probable that water levels were higher and closer to the nest site when eggs were deposited, since water levels fluctuate during nesting season (Polisar, 1996).

We infer that these nests were laid prior to our camera trap deployment in January 2019, as most nesting occurs between September and December (Polisar, 1996; Vogt et al., 2011). In addition, peak water levels occur during this period in the New River, (Hartshorn et al., 1984) so the nest soil was likely saturated or inundated when the eggs were deposited. This is supported by the absence of $D$. mawii at the nesting area based on our camera trap data. It is also possible, that even though we used infrared detection for night time observations, turtles or other reptiles may have visited the site undetected if their body temperatures were the same or very similar to ambient (Richardson et al., 2018). For example, photos of $I$. iguana were captured visiting the $D$. mawii nesting site during the day, but they were not observed at night.

Eggs of $D$. mawii can withstand inundation for more than 30 days (Polisar \& Horwich, 1994; Polisar, 1996), suggesting that they can undergo embryonic diapause (Vogt et al., 2011). Development resumes after water levels recede and the nest is no longer saturated, which at this site would likely occur in January. Hatching occurs when moisture in the nest increases, typically with the summer rains in June and July (Polisar, 1992, 1995). The timing of $D$. mawii nesting at this site on the New River follows this pattern.

Based on our observations of $D$. mawii nesting, we make the following recommendations to researchers and conservationists searching for $D$. mawii nests. In areas that are likely to be inundated for periods exceeding 300 days, seek places with vegetation indicating higher elevation and, hence, periods of shorter inundation ( $<120$ days). In these locations, be watchful for sites with relatively open canopy, and keep in mind that $D$. mawii will nest in areas that are inundated or saturated during the rainy season. Also, be aware that this species can nest communally, especially in areas where nesting habitat is limited. To be thorough, we suggest that nest searches extend inland from the shoreline for at least $25 \mathrm{~m}$ or the width of the elevated area. Improving the ability to identify nesting areas and locate nests will enhance our knowledge of D. mawii nesting ecology and therefore our ability to conserve this critically endangered species.

\section{ACKNOWLEDGEMENTS}

We thank the Lamanai Field Research Center and the University of Florida for supporting our research in Belize.
We thank the Belize Fisheries Department for providing us with the permit to conduct research. Additionally, we thank Mauricio Aguilar who found the nest site and informed guides of the Lamanai Field Research Center of its location. This work would not have been possible without the knowledge, support and time of guides from the Lamanai Field Research Center. We also thank Colette Adams and Curt Harbsmeier for their help in locating the hicatee nests and excavating hatchlings.

\section{REFERENCES}

Briggs-Gonzalez, V., Gonzalez, S.C., Smith, D., Rainwater, T.R. \& Mazzotti, F.J. (2019). Species bioprofile for the hicatee (Dermatemys mawii). Caribbean Naturalist 2: 156-176.

Briggs-Gonzalez, V., Gonzalez, S.C., Smith, D., Allen, K., Rainwater, T.R. \& Mazzotti, F.J. (2018). Dermatemys mawii (the hicatee, tortuga blanca or Central American river turtle): A working bibliography. Caribbean Naturalist 2: 1-22.

CITES (2009). Convention on International Trade in Endangered Species of Wild Fauna and Flora http://www.cites.org.

García-Anleu, R., McNab, R.B., Shoender, J.S., Espejel, V., Moreira, J., Ponce, G., Ramos, V.H., Oliva, F., González, E., Tut, H., Tut, K., Xol, T., Xoc, P., Córdova, M., Córdova, F. \& Morales, L. (2007). Distribution and Ecology of the Central America River Turtle (Dermatemys mawii: Dermatemydidae) in the Lowland Maya Forest, Guatemala. Wildlife Conservation Society-Guatemala Program, Guatemala. 28 pp.

Hartshorn, G., Nicolait, L., Hartshorn, L., Bevier, G., Bightman, R., Cal, J., Cawich, A., Davidson, W., Dubois, R., Dyer, C., Gibson, J., Hawley, W., Leonard, J., Nicolait, R., Weyer, D., White, H. \& Wright, C. (1984). In Belize Country Profile: a Field Study, pp 11-13. USAID and Robert Nicolait and Assoc., Ltd., Belize City, Belize.

IUCN (2009). International Union for Nature and Natural Resources (IUCN) Red List of Threatened Species. http:// www.iucnredlist.org.

Moll, D. (1986). The distribution, status, and level of exploitation of the freshwater turtle Dermatemys mawii in Belize, Central America. Biological Conservation 35: 8796.

Moll, D. (1994). The ecology of sea beach nesting in slider turtles (Trachemys scripta venusta) from Caribbean Costa Rica. Chelonian Conservation and Biology 1: 107-116.

Moll, D. \& Moll, E.O. (1990). The slider turtle in the neotropics: adaptation of a temperate species to a tropical environment. In Life History and Ecology of the Slider Turtle, Chapter 12, pp. 152-161. J. Whitefield Gibbons (Ed.), Smithsonian Institution Press. Washington D.C.

Moll D. \& Moll E.O. (2004). The Ecology, Exploitation, and Conservation of River Turtles. New York: Oxford University Press. $404 \mathrm{pp}$.

Platt, S.G., Barrett H.A., Marlin, J.A., Pop, T., Serano J. \& Rainwater T.R. (2019). Dermatemys mawii (Central American River Turtle). Morphometrics, description, and photographs of neonates. Herpetological Review 50: 8586.

Polisar, J. (1992). Reproductive biology and exploitation of the 
Central American river turtle Dermatemys mawii in Belize. Masters Thesis, University of Florida, Gainesville. 179 pp.

Polisar, J. (1994). New legislation for the protection and management of Dermatemys mawii in Belize, Central America. Herpetological Review 25: 47-49.

Polisar, J. (1995). River turtle reproductive demography and exploitation patterns in Belize: Implications for management. Vida Silvestre Neotropical 4: 10-19.

Polisar, J. (1996). Reproductive biology of a flood-season nesting freshwater turtle of the northern neotropics: Dermatemys mawii in Belize. Chelonian Conservation and Biology 2: 13-25.

Polisar, J. \& Horwich, R. (1994). Conservation of the large economically important river turtle Dermatemys mawii in Belize. Conservation Biology 8: 338-342.

Rainwater, T.R., Pop, T., Cal, O., Garel, A., Platt, S. \& Hudson, R. (2012). A recent countrywide status survey of the critically endangered Central American river turtle (Dermatemys mawii) in Belize. Chelonian Conservation and Biology 11: 97-107.
Richardson, E., Nimmo, D.G., Avitabile, S., Tworkowsi, L., Watson, S.J, Welbourne D. \& Leonard, S.W. (2018). Camera traps and pitfalls: an evaluation of two methods for surveying reptiles in a semiarid ecosystem. Wildlife Research 44: 637-647.

Vogt, R.C. (1990). Reproductive Parameters of Trachemys scripta venusta in Southern Mexico. In Life History and Ecology of the Slider Turtle, J. Whitefield Gibbons (ed.). Smithsonian Institution Press. Washington D.C.13: 162168.

Vogt, R.C. \& Flores-Villela, O. (1992). Effects of incubation temperature on sex determination in a community of neotropical freshwater turtles in southern Mexico. Herpetologica 48: 265-270.

Vogt, R.C., Polisar, J.R., Moll, D. \& Gonzalez-Porter, G. (2011). Central American river turtle, tortuga blanca, hicatee. Conservation Biology of Freshwater Turtles and Tortoises; A Compilation Project of the IUCN/ SSC Tortoise and Freshwater Turtle Specialist Group. Chelonian Research Monographs 5: 058.1-058.12.

Accepted: 2 April 2020 